\title{
ANTIDROMIC AND TRANS-SYNAPTIC ACTIVATION OF DEITERS' NEURONES INDUCED FROM THE SPINAL CORD
}

\author{
M. Ito, T. HonGo*, M. YoshidA**, Y. OKAdA**** \\ AND K. OBATA \\ Department of Physiology, Faculty of Medicine, \\ University of Tokyo
}

The lateral vestibular nucleus of Deiters is characterized by containing the giant-sized neurones. As the origin of the vestibulospinal tract, its function is thought to mediate facilitatory influences onto spinal motoneurones (cf. Gernandt, Iranyl \& Livingston, 1959; Gernandt \& Gilman, 1959). Recently, histological works by BRODAL and his colleagues (cf. BrodAL, POMPEIANO \& WALBERG, 1962) have greatly advanced the knowledge of the cytoarchitecture and fibre connexions in this nucleus. On the other hand, electrical activities of individual Deiters' neurones have so far been investigated by several workers by means of the extracellular recording of unit spike discharges which were located within the nucleus of Deiters by the histologically controlled stereotaxic micromanipulation (DE VITO, BRUSA \& ARDUINI, 1956; Pompeiano \& CotTi, 1959). In order to obtain further information on the performance of Deiters' neurones, not only the extracellular but also the intracellular recording techniques have been employed in the present investigation. As the initial step, a systematic exploration was made of the potential changes occurring in the region of the vestibular nuclei during stimulation of the spinal cord. As will be described in this paper, activation of the vestibulospinal tract induces conspicuous field potentials in the nucleus of Deiters such as occur in the spinal motor nucleus under stimulation of the ventral root (cf. FATT, 1957). Individual neurones were impaled within the region specified by these field potentials and this paper will also deal with action potentials and postsynaptic potentials therefrom recorded intracellularly during stimulation of the spinal cord.

Received for publication August 18, 1964

Addresses: * Department of Physiology, Tokyo Medical and Dental University. ** Department of Neuropsychiatry, Faculty of Medicine, University of Tokyo. *** Neurophysiological Section, Institute of Brain Research, Faculty of Medicine, University of Tokyo.

伊藤正男, 本郷利憲, 吉田充男, 岡田安弘, 小幡邦彦 
Preliminary report has already been published (ITO, Hongo, YosHidA, OKADA \& OBATA, 1964).

\section{METHODS}

Preparations. Twenty-eight cats were used. They were anaesthetized by intraperitoneal injection of pentobarbitone sodium $(30 \mathrm{mg} / \mathrm{kg})$. For inserting the microelectrode into the vestibular nuclei region, the way of pharyngeal approach was mainly adopted. After tracheal cannulation, the trachea and the oesophagus were cut at the third cervical level and their oral ends were reflected. The head of the cat was mounted on a stereotaxic apparatus upside down (FIG. 1) and the base of the skull was opened between tympanic bullae. The dura was opened so that the ventral surface of the medulla was visualized for about $5 \mathrm{~mm}$ caudally from the edge of the pons (FIG. 1B). The $\mathrm{C}_{3}$ vertebra was clamped rigidly and its body was drilled through from the
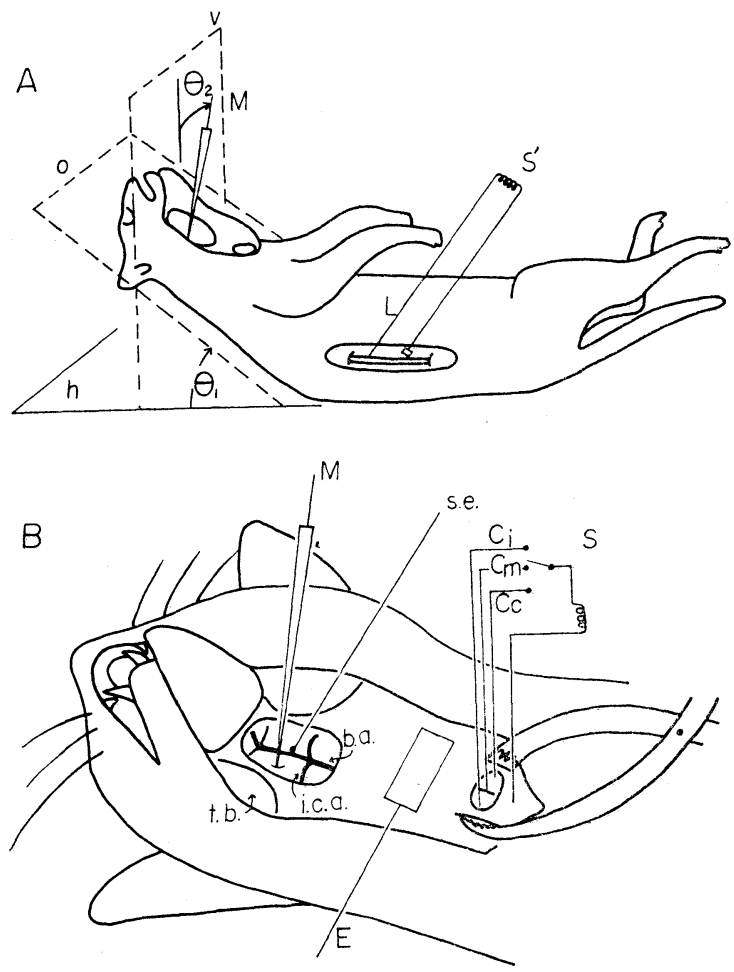

FIG. 1. Diagrams showing arrangement used for microelectrode experiments on Deiters' neurones. A, h, horizontal plane mounting the cat body. v, vertical plane at right angle to $\mathrm{h}$ and to the sagittal plane of the cat's head. o, oblique plane at right angle to the sagittal and transverse planes of the cat's head. M, microelectrode, L, stimulating electrode placed at the $\mathrm{L}_{1}$ segment, $\mathrm{S}$, stimulator. B, t.b., tympanic bulla, b. a., basilar artery, i.c. a., inferior cerebellar artery. s. e., surface electrode. $\mathrm{E}$, indifferent electrode, $\mathrm{C}_{i}, \mathrm{C}_{m}, \mathrm{C}_{c}$, silver wire electrodes placed on the $\mathrm{C}_{3}$ segment. $\mathrm{S}$, stimulator. Further explanations in text. 
ventral side so as to expose the $\mathrm{C}_{3}$ segment of the spinal cord for about $5 \mathrm{~mm}$ across. The dissected tissues at the neck were immersed in a paraffin pool held by skin flap (Fig. 1A, B). The cat body was laid with the left flank down, and the $T_{12}$ and $L_{3}$ vertebrae were held rigidly by metal clamps, while the $T_{13}$ to $L_{2}$ vertebrae were laminectomized. The exposed thoracicolumbal cord was also immersed in a separate paraffin pool (FIG. 1A).

In the earlier experiments the nucleus of Deiters was approached with the cat which was rightly placed in a sphinx position. The floor of the fourth ventricle was cleared for insertion of microelectrodes by complete removal of the cerebellum or else by lifting up its posterior lobe. However, since these procedures damaged the brain tissue to a much greater extent than the pharyngeal approach mentioned above, the latter has been preferred throughout the later experiments.

Microelectrodes and micromanipulation. Glass microelectrodes were filled with solution containing $3 \mathrm{M} \mathrm{KCl}$ or $2 \mathrm{M} \mathrm{NaCl}$ and those with electrical resistance of 7 to $15 \mathrm{M} \Omega$ were selected. An electrode was attached to a micromanipulator of the same type as that employed by Eccles, FAtT, LANDGREN \& Winsbury (1954) and inserted in the ventro-dorsal direction into the brain stem on the right side, at a point about $2 \mathrm{~mm}$ lateral from the anterior median fissure and 2 to $5 \mathrm{~mm}$ caudal from the edge of the pons. It was advanced in a vertical plane (FIG. 1Av) at right angle to the sagittal plane of the cat head. When the cat's head was held horizontally, the inferior cerebellar artery and accompanying veins usually lay on the way of the microelectrode tracks which aimed at the nucleus of Deiters (see Fig. 1B). Therefore, except for the earlier experiments, the cat head was fixed at ventroflexion of 20 degrees $\left(\theta_{1}\right.$ in FIg. 1A), so that the nucleus of Deiters was accessible through a wide area of the medullary surface between the caudal edge of the pons and the inferior cerebellar artery.

As shown in Figs. 2B and 3E, on a transverse plane of the brain stem, the microelecrode reached the nucleus of Deiters at the depth of 5 to $7 \mathrm{~mm}$ when a lateral angle $\left(\theta_{2}\right.$ in FIG. 1A) of 10 to 20 degrees was taken. A systematic tracking through the vestibular nuclei region was made by changing the lateral angle (see Figs. 2 and 3 ). Contact of the electrode tip with the medullary surface was controlled under direct vision of the binocular microscope with magnification of up to 60 .

Arrangements for recording and stimulation. A ball-tipped platinum electrode was placed on the ventral surface of the medullary pyramid, usually just at the left side of the basilar artery near the site of penetration with microelectrodes (FIG. 1B, s. e.). This surface electrode was connected to a high gain a.c. amplifier for monitoring the synchronized volleys produced by stimulating the spinal cord (see below). The microelectrode was connected to the input circuit designed by ITo (1960) for both recording and passing currents. Its high frequency characteristics were improved by the controlled positive feedback. After d.c. or a.c. amplification, the potential changes detected by the microelectrode were displayed on one beam of the dual beam oscilloscope, the surface potential of the medulla being shown on the other. A large silver plate (area, about $5 \mathrm{~cm}^{2}$ ) was mounted on the $\mathrm{C}_{2}$ vertebra as the indifferent electrode (FIG. 1B) and was connected to the earth through a low impedance calibrator and a generator of the backing voltage.

Three electrodes of silver wire, coated by enamel except at the very tips, were placed on the ventral surface of the exposed $C_{3}$ segment, one on the anterior median fissure and the other two at about $2 \mathrm{~mm}$ lateral from the former on the right and the left sides, respectively. They were used one at a time as cathode for stimulation 
against anode, which was a silver wire touching on the $C_{3}$ vertebra (FIG. 1B). For stimulating the $\mathrm{L}_{1}$ segment, a platinum electrode was also placed at $2 \mathrm{~mm}$ lateral from the anterior median fissure on the right side, while its partner electrode was a silver plate mounted on the back muscles (FIG. 1A). Stimuli were provided by condensor discharge shocks with time constant of 50 to $100 \mu \mathrm{sec}$ and their amplitude varied within the range of $15 \mathrm{~V}$.

Anatomical and histological check. After each experiment the cat was sacrificed by administrating a large dose of pentobarbitone sodium intravenously, while the microelectrode was left in a track through the brain stem. The brain tissue was then fixed by injecting $10 \%$ formalin solution into the carotid artery. The distances between the entrance of the microelectrode track and the stimulating sites at the $\mathrm{C}_{3}$ and $\mathrm{L}_{1}$ segmental levels were measured by laminectomizing through the all cervicothoracic segments or, for the $\mathrm{C}_{3}$ to $\mathrm{L}_{1}$ levels, by passing a flexible wire through the spinal canal. The shaft of the microelectrode was cut by scissors, and the brain stem and cerebellum with the electrode tip inserted were dissected out. They were stored in a solution containing $10 \%$ formalin and $0.9 \% \mathrm{NaCl}$. Within several weeks thereafter, serial frozen sections were made at $40 \mu$ thickness transversely through the brain stem and cerebellum, in parallel with the shaft of the buried microelectrode. The electrode was pulled out before the knife reached its level, but its track was easily found over several sections. They were mounted on glass plates and stained with $0.1 \%$ methylene blue solution. The contours of the stained structures were traced under a photographic enlarger as shown in Figs. $2 \mathrm{~B}$ and $3 \mathrm{E}$. They were object to a further histological examination by KLÜVAR-BARRERA staining method. No correction was made for the possible shrinkage of the brain tissue in illustrations of FIGs. $2 \mathrm{~B}$ and $3 \mathrm{E}$.

\section{RESULTS}

Field potentials induced by stimulation of the spinal cord. When a stimulus was applied to the $\mathrm{C}_{3}$ segment by one of the three electrodes set thereon, a spike potential was picked up by the surface electrode on the medulla (FIG. 2A surf., FIG. 3C). This potential would be generated by the impulses travelling up the spinal cord through the ventrolateral funiculi, including that along the vestibulospinal tract which passes through the ventral half of the lateral funiculus of the cervical cord (PompeIANO \& BRODAL, 1957a). In the case of FIG. 2, a microelectrode was inserted into the brain stem on the right side along five tracks of different lateral angles to the depth of more than $10 \mathrm{~mm}$. In the course of withdrawing the microelectrode, the potential changes were recorded in $100 \mu$ steps, while the $\mathrm{C}_{3}$ segment was excited by the ipsilateral electrode with stimuli supramaximal for the surface-recorded spike potential. Specimen records in FIG. 2A show that at a depth of about 5 to $8 \mathrm{~mm}$ large negative potentials are evoked following a small positive phase (see also traces at 9.1 and $8.7 \mathrm{~mm}$ of FIG. 4A). Their latency was as short as $0.5 \mathrm{msec}$ and their amplitude amounted to several millivolts. As shown in FIG. 2B, when the limit was taken at $250 \mu \mathrm{V}$ (dotted line) or $500 \mu \mathrm{V}$ (interrupted line), these negativities of significant sizes were found to arise only from a well- 
circumscribed area 2 to $3 \mathrm{~mm}$ across. When compared with the histological section of the brain stem in which the microelectrode track was located (see Methods), the area specified by the field potential was always found to correspond to the histologically identified nucleus of Deiters. The agreement was

A

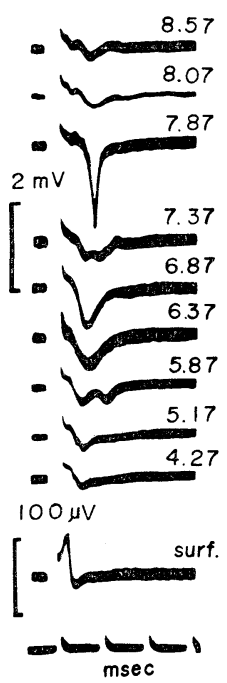

B

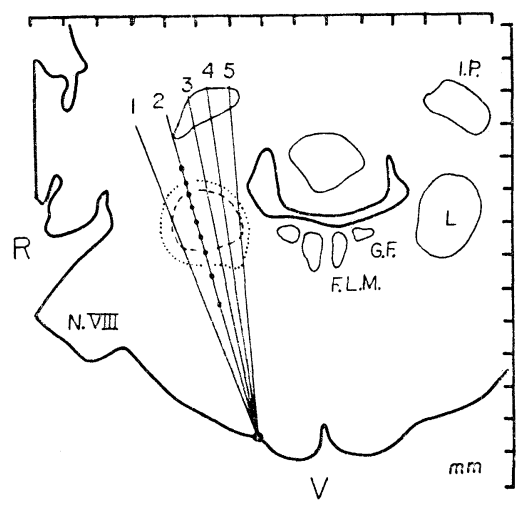

FIG. 2. A, potential changes recorded with a microelectrode along a track through the nucleus of Deiters. Figures attached to the right of each record indicate the depth of recording from the medullary surface in $\mathrm{mm}$. In this as well as in the succeeding figures, positivity is represented by upward deflection except for the bottom record labelled surf. which was registered on the medullary surface. Twenty to forty faint traces were superimposed in each record. The $\mathrm{C}_{3}$ segment was stimulated ipsilaterally. Voltage scale of $100 \mu \mathrm{V}$ applies only to surf. $B$, diagram showing the transverse section of the brain stem and the cerebellum. The angle $\theta_{1}$ (see Fig. 1A) was zero in this case. L, I.P., G.F., F.L.M., histologically identified nucleus of Deiters, nucleus interpositus, genu facialis and fasciculus longitudinalis medialis, respectively. N. VIII, 8th nerve. R, right, V, ventral. Five thin lines (1-5) drawn in the right side of this section indicate the microelectrode tracks. The track 2 was used for recording the potential changes of A and was found histologically on this section. Filled circles on the track 2 indicate the position of recording each trace of $\mathrm{A}$. The dotted and interrupted lines enclose the area within which negativity of more than 250 and $500 \mu \mathrm{V}$, respectively, were obtained.

excellent even when the shrinkage of the brain tissue and errors in superposing the electrode tracks on the section were taken into consideration (FIG. 2B). Consequently, the negative field potentials can be ascribed to the activities of Deiters' neurones which are excited antidromically through the vestibulospinal tract. This view is supported by the results of the intracellular recording from individual Deiters' neurones (see below). 
In the case of FIG. 3 nine tracks of different lateral angles covered a wide area of the brain stem and the pronounced electric field potentials were also found in the region of the nucleus of Deiters along the tracks 1 to 4 during stimulation at the $\mathrm{C}_{3}$ segment. Within this area (shaded in FIG. 3E) the threshold voltage for evoking the field potential was always lowest with the ipsilateral cervical electrode (FIG. 3Ai, 2.5 V) and, conversely, highest with the contralateral one, while it was intermediate at the central position (FIG. $3 \mathrm{Am}, 5.0 \mathrm{~V}$ ). Though with relatively strong stimuli the field potential could be evoked by anyone of the three cervical electrodes (FIG. 3A, 12.5 V), the above-described threshold discrimination suggested that the pathway responsible for producing the field potential was on the ipsilateral side, in keeping with the histological finding that the vestibulospinal tract is exclusively

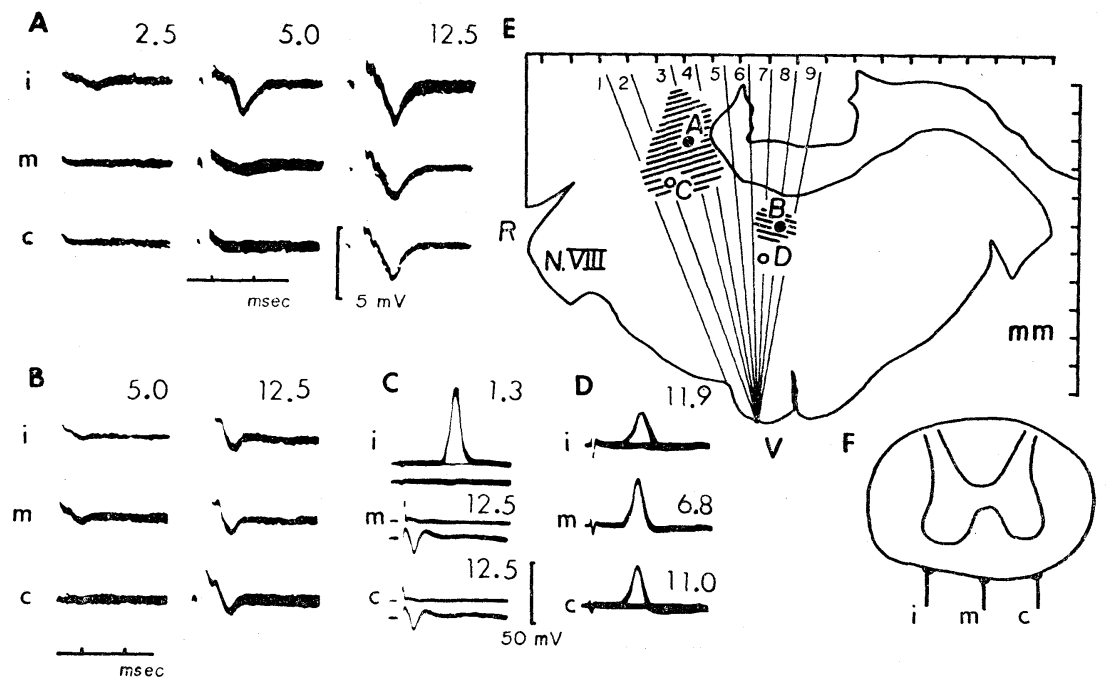

FIG. 3. A, field potentials recorded within the nucleus of Deiters at the site indicated by a closed circle $\mathrm{A}$ in $\mathrm{E}$. $\mathrm{i}, \mathrm{m}$ and $\mathrm{c}$ mean ipsilateral, middle and contralateral $\mathrm{C}_{3}$ stimulation. Figures on each column of records indicate the intensities of the $\mathrm{C}_{3}$ stimulation in volts. $\mathrm{B}$, field potentials obtained at the position medial to the nucleus of Deiters (closed circle B in E). Same notations as in A. C, spike potential recorded intracellularly from a Deiters' neurone (at the position of the open circle $\mathrm{C}$ in $\mathrm{E}$ ). Stimulus intensity is indicated on each record of $\mathrm{i}, \mathrm{m}$ and $\mathrm{c}$. Note that the spike was induced only from the ipsilateral $\mathrm{C}_{3}$ segment within the range of $12.5 \mathrm{~V}$. D, spike potential of a reticular formation neurone (at the position of the open circle D in E). Same notations as in C. E, transverse plane of the brain stem and the cerebellum. The angle $\theta_{1}$ (FIG. 1A) was 20 degrees in this case. $R$, right, $V$, ventral. Thin solid lines (1-9) represent microelectrode tracks. Field potentials of more than $250 \mu \mathrm{V}$ were recorded from the shaded regions during stimulation of the ipsilateral $\mathrm{C}_{3}$ segment with $12.5 \mathrm{~V}$. $\mathrm{F}$, transverse section of the $\mathrm{C}_{3}$ segment. $\mathrm{i}, \mathrm{m}$ and $\mathrm{c}$, ipsilateral, middle and contralateral $\mathrm{C}_{3}$ electrodes, respectively. 
homolateral (POMPEIANO \& BRODAL, 1957a). A relatively small field potential was also detected in the region medial to the nucleus of Deiters (shaded along the tracks 7 to 9 in FIG. 3E). The threshold for initiating this, however, was lowest with the middle cervical electrode (FIG. 3B, $5.0 \mathrm{~V}$ ), being only slightly higher with the other lateral two. It is likely that this field is caused by impulses up the fibres different from those in the vestibulospinal tract, such as in the fasciculus longitudinalis medialis (see FIG. 2B) which runs through the ventral funiculus.

In the records of FIG. $4 \mathrm{~A}$ and $\mathrm{B}$ the field potentials were induced by stimulating the $\mathrm{C}_{3}$ and the $\mathrm{L}_{1}$ segment, respectively, on the ipsilateral side and were recorded along a track through the nucleus of Deiters. As would be expected, the $\mathrm{L}_{1}$-induced responses had a much longer latency ( $2.4 \mathrm{msec}$ ) than the $\mathrm{C}_{3}$-evoked ones $(0.6 \mathrm{msec})$, The marked scattering of the negativities in $\mathrm{B}$ would be due to dispersion in the conduction velocity along the axons of Deiters' neurones (see below). As a measure of the antidromically induced
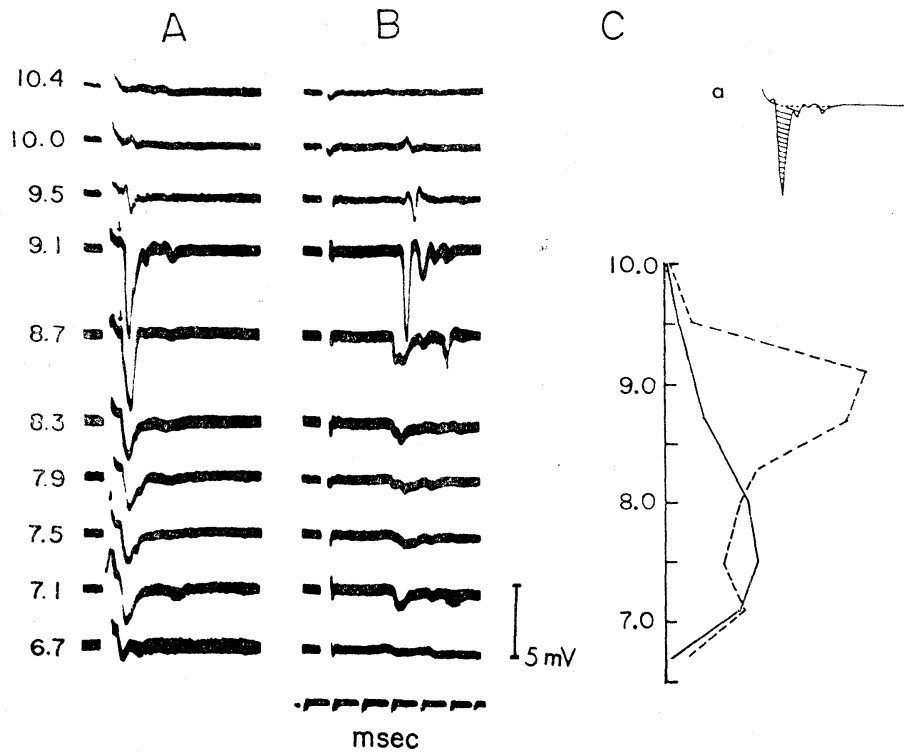

FIG. 4. A, field potentials recorded along a track through the nucleus of Deiters during ipsilateral $C_{3}$ stimulation with $12.5 \mathrm{~V}$. Figures to the left of each record indicate in $\mathrm{mm}$ the depth of recording measured from the medullary surface. Downward arrows mark the small positive phase preceeding the negativity. B, field potentials recorded under ipsilateral $\mathrm{L}_{1}$ stimulation at the same depth as in A. $\mathrm{C}$, interrupted line indicates the time integral of the negative phase of the field potentials in the records of $B$, as function of the depth in $\mathrm{mm}$. Unit of the abscissae is arbitrary. The solid line shows the difference of integrated negativities between $A$ and $B$. The area of the negative phase was measured after correcting for the artifact potential following the stimuli as illustrated in the inset figure (a). 
activities in the nucleus of Deiters, the area enclosed by the negative phase of the field potential was estimated by a planimetre (see legend of FIG. 4). In FIG. $4 \mathrm{C}$ the interrupted line indicates the $\mathrm{L}_{1}$-induced activity thus measured, which should have occurred in Deiters' neurones innervating the lumbosacral segments. On the other hand, the solid line represents the difference between the $\mathrm{C}_{3}$ - and $\mathrm{L}_{1}$-induced responses, i. e., the activity of Deiters' neurones sending axons to the cervicothoracic spinal cord except for the $\mathrm{C}_{1}$ and $\mathrm{C}_{2}$ segments. It is seen that the lumbosacral activity predominates in the dorsal region of the nucleus, while the cervicothoracic one is highest at the relatively ventral. region. This pattern of the relative predominance between the lumbosacral. and cervicothoracic activities was regularly seen along ventrodorsal tracks, in agreement with the somatotopical distribution in the nucleus of Deiters determined by a histological method (PompeIano \& BRODAL, 1957a) (see Discussion).

Impalement of Deiters' neurones. Within the nucleus of Deiters thus identified unequivocally by the antidromic field potentials, unit spikes were of ten picked up extracellularly, i.e., without appearance of the resting potential. They were either large negative spikes with a small later positive phase (FIG. 5A), or negative-positive (B) or positive-negative (C) diphasic spikes. Amplitude of the former two was usually within $5 \mathrm{mV}$, while that of the last of ten was as large as $20-40 \mathrm{mV}$. This so-called giant extracellular spike (Granit \& Phillips, 1956; Crain, 1956; Freygang, 1958; Freygang \& Frank, 1959) showed an inflection on its rising phase (marked by an arrow in FIG. 5C). The similar variety of the extracellular spikes has been studied in cat's spinal motoneurones (TERZUOLO \& ARAKI, 1961). When an extracellular spike was seen, the microelectrode was advanced carefully and currents of $10^{-7} \mathrm{~A}$ or so were passed through the electrode intermittently. Particularly when the giant extracellular spike was detected, passage of currents was effective in introducing the electrode tip into the cell, presumably by destroying obstacles under the electrode tip (cf. ITO, 1959).

When a cell was penetrated, the resting potential of -50 to $-70 \mathrm{mV}$ suddenly appeared and spike potentials were set up by stimulation of the $\mathrm{C}_{3}$. segment at a short latency of 0.4 to $1.9 \mathrm{msec}$ (mean of 134 cells, $0.93 \mathrm{msec}$ ). As seen in FIG. 5D, these spikes were characterized by an inflection which occurred at about mid-point of their rising phase. When the stimulus intensity was reduced to a certain value, the spike disappeared in an all-or-none manner (FIG. 3Ci), without leaving any prepotentials. In FIG. $5 \mathrm{E}$ and $\mathrm{F}$ two stimuli were given to the $\mathrm{C}_{3}$ segment successively. The inflection of the second spike became more prominent than that of the first one (E) and therefrom a component spike was separated at an appropriate interval of stimulation $(F)$. Further reduction of the interval abolished this component spike, usually leaving a small spike of 1 to $2 \mathrm{mV}$ in amplitude. The general feature 

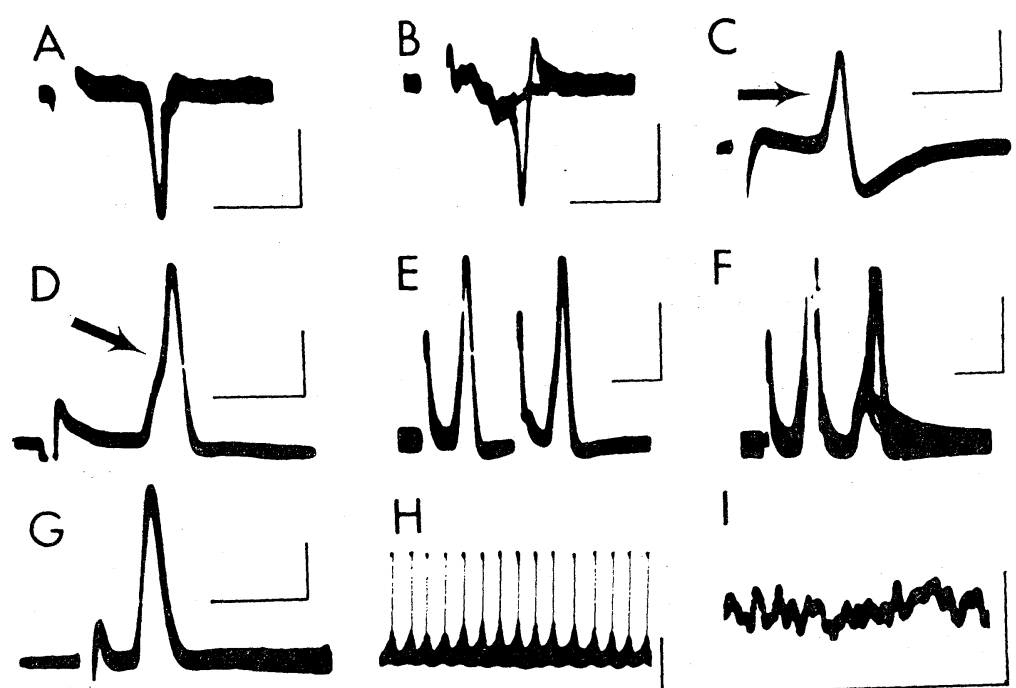

1



FIG. 5. Extracellular and intracellular recording within the nucleus of Deiters during stimulation at the ipsilateral $\mathrm{C}_{3}$ segment. $\mathrm{A}$, extracellular negative unit spike. B, negative-positive unit spike. C. positive-negative unit spike. In $B$ the stimulus was just at threshold so that the antidromic activation failed at about half of the trials, revealing the negative field potential on the base line. Arrow in $\mathrm{C}$ indicates the inflection of the positive phase. $\mathrm{D}$, intracellularly recorded spike. Arrow marks the inflection of the rising phase. E, F, spikes induced by two seccessive stimuli. Intracellular recording. $G$, axonal spike recorded intracellularly. $\mathrm{H}$, repetitive spontaneous discharge. Intracellular recording from a Deiters' neurone. I, irregular spontaneous fluctuation of the membrane potential of a Deiters' neurone. Time scale, $1 \mathrm{msec}$ for $\mathrm{A}-\mathrm{G}, 100 \mathrm{msec}$ for $\mathrm{H}$ and $10 \mathrm{msec}$ for I. Voltage scale, $2 \mathrm{mV}$ for $\mathrm{A}, \mathrm{B}$ and $\mathrm{I}, 20 \mathrm{mV}$ in $\mathrm{C}-\mathrm{H}$.

of the spike potential thus resembles closely that induced antidromically in the spinal motoneurones (Brock, CoOmBs \& Eccles, 1953 ; CoOmBS, CurTis \& ECCLES, 1957). On analogy, it may be assumed that the impaled Deiters' neurones are invaded antidromically in a three-step manner which is comparable with spinal motoneurones, i. e., from the myelinated segment of the axon to the initial segment and further to the soma-dendritic region, producing the M, IS and SD spikes, respectively. As exemplified in FIG. 3C, the antidromic invasion was induced by the ipsilateral electrode with considerably lower threshold intensity than by the middle and contralateral ones. This is to be expected from the homolaterality of the vestibulospinal tract which was indicated above with the negative field potential of this nucleus of Deiters. The spike potentials in FIG. 3D were recorded from the region medial to the nucleus of Deiters (at the site marked by an open circle labelled D in FIG. $3 \mathrm{E})$, presumably from a neurone of the reticular formation. They assumed a configuration with an inflected rising phase similar to that in Deiters' neurones, 
but they were distinguished from the latter by the fact that the threshold for inducing them antidromically was lowest at the middle $\mathrm{C}_{3}$ electrode, being about doubled at the lateral $\mathrm{C}_{3}$ electrodes. It is likely that the axon of this reticular formation neurone passed through the medial portion of the ventral funiculus.

Compared with spinal motoneurones, the Deiters' neurones appeared to be much more susceptible to damage by the microelectrode penetration; the resting potential declined rather rapidly with concomitant deterioration of the spike potential. With the resting potential around $-50 \mathrm{mV}$ the cells of ten fired spontaneously (FIG. $5 \mathrm{H}$ ) and discharge frequencies up to the extent of $400 \mathrm{c} / \mathrm{s}$ were maintained for many minutes. In sixteen cells, nevertheless, spike potentials of more than $60 \mathrm{mV}$ in amplitude (maximum, $100 \mathrm{mV}$; mean, $80.8 \mathrm{mV}$ ) were recorded under a reasonably stable state of the resting potential at the level of -55 to $-75 \mathrm{mV}$. In the majority of them (13 out of 16), the falling phase of the spike undershot the resting potential level by 2 to $5 \mathrm{mV}$ (see FIGS. 5D and 6A), and the duration of the spike was measured as the time from the foot to the point at which the falling phase of the spike crossed the base line. It was as short as 0.4 to $0.6 \mathrm{msec}$ (mean, $0.47 \mathrm{msec}$ ). In three other cells as well, the time course of the spike was comparably fast, though the falling phase of the spike ceased at a level above the resting base line (see FIG. 3Ci).

In one hundred and one out of totally 134 Deiters' neurones impaled, stimulation of the homolateral $\mathrm{L}_{1}$ segment was tried and in sixty-five neurones antidromic invasion was induced. This latter population of the cells is presumed to innervate the lumbosacral segments of the cord, while the axons of the remaining thirty-six would terminate within the cervicothoracic segments. Probably the lumbosacral cells are more easily impaled because they are somewhat larger and more densely packed (Pompeiano \& BRodAL, 1957a). In FIG. 4 the field potentials of different somatotopical origin showed considerable overlapping. Indeed, the impaled neurones were found to be activated from the $\mathrm{L}_{1}$ level, not only within the dorsal but also ventral region of the nucleus where the $L_{1}$-induced field potentials were smaller than the $\mathrm{C}_{3}$-induced ones. Histological observation also points to a considerable overlap between what may be called the lumbosacral and cervicothoracic regions of the nucleus of Deiters (Pompeiano \& Brodal, 1957a).

In contrast to the above described cellular spikes, spikes without inflection on their rising phase were recorded in response to stimulation of the $\mathrm{C}_{3}$ or $\mathrm{L}_{1}$ segment, either within or outside the nucleus of Deiters, particularly in the ventral region to the nucleus which contains the vestibulospinal fibres and in the restiform body through which the spinocerebellar fibres pass (FIG. 5G). Hence they are presumed to be axonal spikes such as have been recorded from the motoneurone axons (COOMBS, ECCLES \& FATT, 1955) or primary 
afferent fibres in the spinal cord (ECCLES \& KRNJEVIĆ, 1959).

Axonal conduction velocity. As shown in FIG. $6 \mathrm{~A}$ and $\mathrm{B}$, when the impaled cell was activated from both the $\mathrm{C}_{3}$ and $\mathrm{L}_{1}$ segments, the conduction velocity along its axon can be calculated as $\left(d_{2}-d_{1}\right) /\left(t_{2}-t_{1}\right)$, where $t_{1}$ and $t_{2}$ are latencies from the $C_{3}$ and $L_{1}$ levels, respectively, as measured from the moment of stimulation to the foot of the intracellularly recorded spikes, and $d_{1}$ and $d_{2}$ are distances between the entrance of the microelectrode into the brain stem and the sites of stimulation at the $\mathrm{C}_{3}$ and $\mathrm{L}_{1}$ levels, respectively. Average values of $d_{1}$ and $d_{2}$ were 4.6 and $25.0 \mathrm{~cm}$, respectively, in ten cats used for this experiment. FIG. $6 \mathrm{D}$ shows the frequency distribution of the conduction velocity thus determined for fifty cells. It varied over a wide range from 24

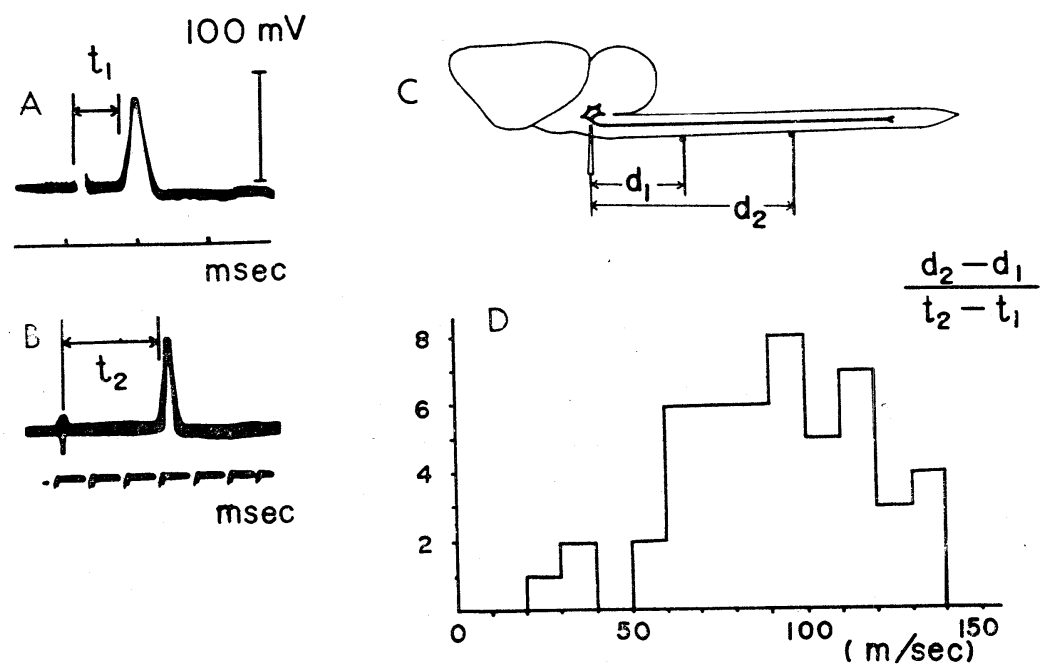

FIG. 6. A, spike potential recorded intracellularly from a Deiters' neurone during stimulation of the $\mathrm{C}_{3}$ segment. $t_{1}$, latency of activation. $B$, that from the $L_{1}$ segment with the latency $t_{2}$. C, diagram showing the conduction distances. along the vestibulospinal tract. Note that $d_{1}$ and $d_{2}$ were measured from the sites of stimulation to the entry of the microelectrode into the brain stem, along the ventral surface of the medulla and cord. D, frequency distribution of the conduction velocity in Deiters' neurones. Ordinates, the number of cells. Abscissae, conduction velocity calculated from $\left(d_{2}-d_{1}\right) /\left(t_{2}-t_{1}\right)$.

to $140 \mathrm{~m} / \mathrm{sec}$ with a peak frequency at 90 to $100 \mathrm{~m} / \mathrm{sec}$. If HuRsH's proportion factor between the conduction velocity and the fibre diameter (HURSH, 1939) holds for the vestibulospinal tract, its fibre spectrum would cover a wide range from 4 to $23 \mu$ with the peak at $16 \mu$. Under the general assumption that larger cells issue thicker axons, these results are consistent with the histological finding that the nucleus of Deiters involves not only giant cells but also medium and small sized neurones which, practically all, send axons. 
down into the spinal cord (Brodal \& Pompeiano, 1957 ; Pompeiano \& Brodal, 1957a).

When calculated in the cells of FIG. $6 D$, the ratio of $d_{1} / t_{1}$ was considerably smaller than the conduction velocity given by $\left(d_{2}-d_{1}\right) /\left(t_{2}-t_{1}\right)$, by about $30 \%$ of the latter. One of the causes of this discrepancy would be that in the brain stem region the vestibulospinal tract shifts in the ventrodorsal direction so as to run over a longer stretch than $d_{1}$, which was measured along the ventral surface of the medulla. This underestimate of the conduction distance, however, would not be more than $15 \%$, because $d_{1}$ is $4.6 \mathrm{~cm}$ on the average (see above) and the depth of the nucleus of Deiters from the ventral surface of the medulla is 5 to $7 \mathrm{~mm}$ (see FIGs. 2B and $3 \mathrm{E}$ ), and hence it would account for only a half of the discrepancy between $d_{1} / t_{1}$ and $\left(d_{2}-d_{1}\right) /\left(t_{2}-t_{1}\right)$. The remaining half would be attributable to the following two reasons; the latency for initiating impulses at the very site of the stimulation would lead to an overestimate of $t_{1}$ as the conduction time, and the conduction velocity itself might be slowed down as the impulses approach the cell soma, because the safety factor of conduction would fall down owing to the low impedance across the soma-dendritic membrane.

Afterpotential. The falling phase of the intracellularly recorded spikes was followed by an afterhyperpolarization (FIG. 7A), either with or without an interposed dip (see FIGS. 3C, 5D and 6A). In the cells with the spike amplitude of more than $60 \mathrm{mV}$ (see above), the peak amplitude of the afterhyperpolarization was between 1.4 and $8.6 \mathrm{mV}$ (mean of 13 cells, $3.8 \mathrm{mV}$ ) and so between 1.2 and $9.9 \%$ of the spike height (mean, 4.3\%). Its summit time was measured from the moment where the falling phase of the spike passed into hyperpolarization (see above) and was 0.7 to $2.7 \mathrm{msec}$ except for $8.8 \mathrm{msec}$ obtained in only one case (mean of 12 cells, $2.4 \mathrm{msec}$ ). After attaining at the summit, the afterhyperpolarization declined rapidly for about 1 to $2 \mathrm{msec}$ and then, with a noticeable inflection (marked by arrows in FIGS. 7A and 9A), was followed by a slower recovery phase, the end point being somewhat indeterminate. ECCLES, ECCLES \& LUNDBERG (1958) measured the duration of the afterhyperpolarization of motoneurones to the summit of the terminal depolarization following the afterhyperpolarization (cf. also ECCLES, ECCLES, IGGO \& ITO, 1961; GILL \& Kuno, 1963). However, the terminal depolarization was not always clear in Deiters' neurones (see FIG. 7A) and hence the duration was measured to the point where the hyperpolarization passed to the original level, as done by KUNO (1959) on lumbar motoneurones. In thirteen cells it ranged from 33 to $100 \mathrm{msec}$, the average being $49 \mathrm{msec}$. In comparison with the afterhyperpolarization of the spinal motoneurones (BROCK et al., 1953 ; Eccles et al., 1958; Kuno, 1959; ECcles et al., 1961), that of Deiters' neurones is thus significantly shorter in its time course, both in the initial 
and declining phases (see Discussion). There are in all thirty cells with spikes of more than $40 \mathrm{mV}$ in amplitude in which the afterhyperpolarization was. recorded. The conduction velocity of these cells ranged from 60 to $110 \mathrm{~m} / \mathrm{sec}$, and had no obvious correlation either with the summit time or the total duration of the afterhyperpolarization.

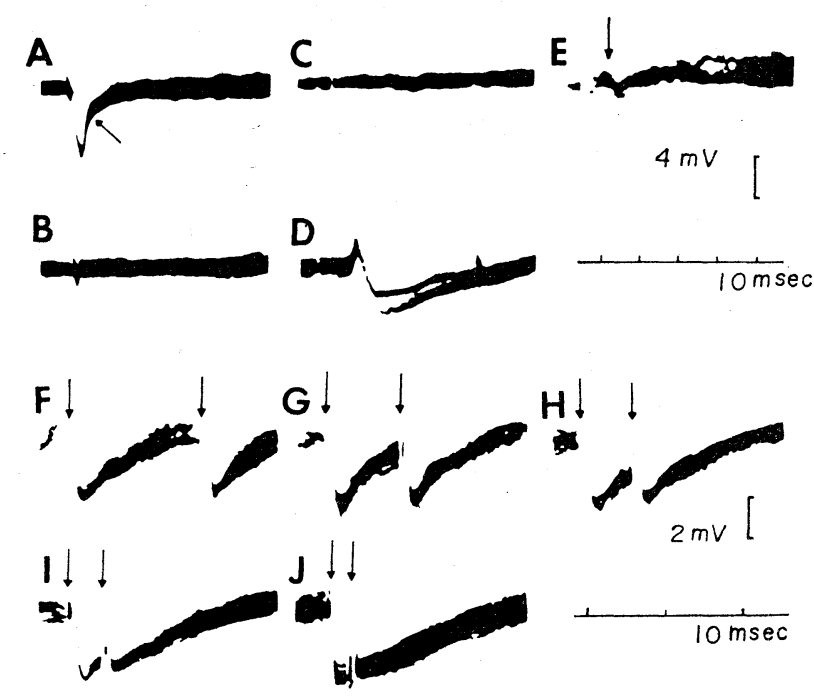

FIG. 7. A, afterhyperpolarization following a spike of a Deiters' neurone. The $\mathrm{C}_{3}$ stimulation was just slightly above the threshold of the axon of this cell. Arrow marks the inflection on the recovery phase of the afterhyperpolarization. $B$, showing the base line for $A$ obtained with the $C_{3}$ stimulation just below the threshold. $\mathrm{C}$, middle $\mathrm{C}_{3}$ stimulation. $\mathrm{D}$, contralateral $\mathrm{C}_{3}$ stimulation. $\mathrm{A}-\mathrm{D}$ were obtained in one and the same neurone. E, patential changes induced in another Deiters' neurone by ipsilateral $\mathrm{C}_{3}$ stimulation, just below the threshold for antidromic activation of this cell. Downward arrow marks the moment of onset of an IPSP. F-J, afterhyperpolarizations induced by two successive stimuli given to the $\mathrm{C}_{3}$ segment, in a Deiters' neurone different from that in A to E. Downward arrows indicate the moments of stimulation.

Another pronounced discrepancy between the afterhyperpolarizations in Deiters' neurones and motoneurones was that, when induced at short intervals, the afterhyperpolarization summates to give a larger hyperpolarization in lumbosacral motoneurones (ITO \& Oshima, 1962), but not in the former, as shown in FIG. $7 \mathrm{~F}$ to $\mathrm{J}$. The potential change at the peak of the second afterhyperpolarization was even reduced as the interval was shortened (FIG. 7I and J). Thus, in respect of the afterpotential the membrane of Deiters' neurones is significantly different from that of lumbar motoneurones. It is interesting that in cat's spinal ganglion cell the afterhyperpolarization is of short duration (less than $20 \mathrm{msec}$ ) and does not show temporal summation (ITO \& Oshima, unpublished). 
Postsynaptic potentials induced from the spinal cord. In the record of FIG.7B. the stimulus intensity given to the ipsilateral $\mathrm{C}_{3}$ segment was held just below the threshold for the axon of the impaled cell. There was no visible potential change following the small initial field potential that was induced antidromically (see above). The same examination as this was done in twenty-six neurones, in twenty out of which no postsynaptic potentials were found to occur. In the two other cases, as exemplified in FIG. 7E, a hyperpolarization, presumably an inhibitory postsynaptic potential (IPSP) was induced at a latency of 6 to $9 \mathrm{msec}$. In the remaining four cells, there was seen a depolarization, presumably an excitatory postsynaptic potential (EPSP) immediately following the antidromic field potential (FIG. 8A). After correcting for the potential change due to antidromic field potential, it was indicated that the net transmembrane depolarization occurred at a latency as short as $1 \mathrm{msec}$ (FIG. 8C), which was comparable with the average latency for the antidromic invasion (see above, $0.93 \mathrm{msec}$ ). Apparently it occurred monosynaptically through fast-conducting fibres; when the single synaptic delay is taken as $0.5 \mathrm{msec}$ (cf. ARAKI, ECCLES \& ITO, 1960), the presynaptic volley should have
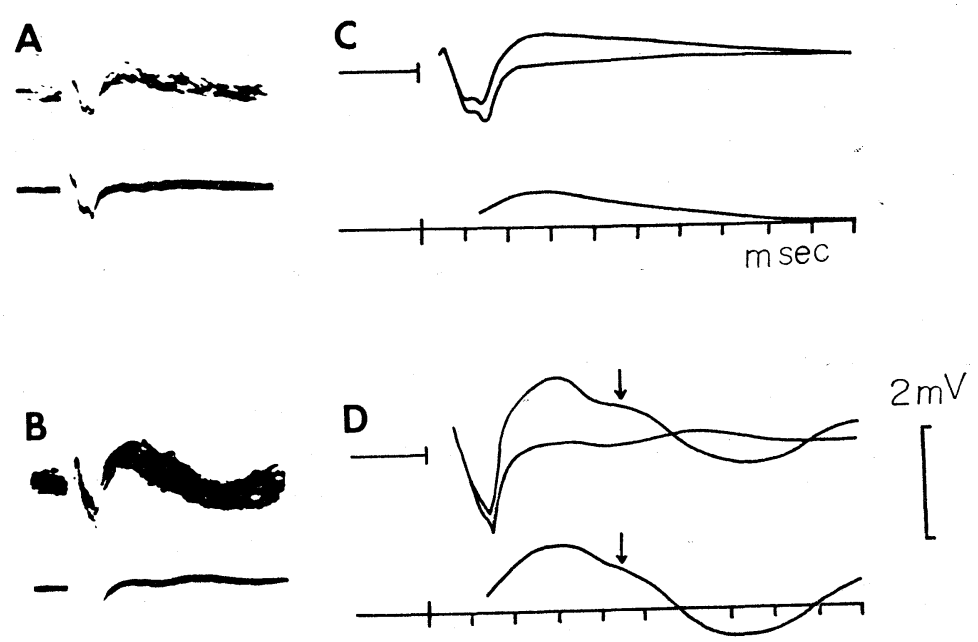

FIG. 8. EPSP induced in a Deiters' neurone by ipsilateral $\mathrm{C}_{3}$ stimulation. A and $\mathrm{B}$, upper traces are intracellular records and lower ones extracellular just outside the cell. Stimulus intensity, $7 \mathrm{~V}$ in $\mathrm{A}$ and $12.5 \mathrm{~V}$ in $\mathrm{B}$, respectively. The latter was above the threshold for the axon of this cell, but at the stage of this recording the antidromic invasion failed due to deterioration. $\mathrm{C}$ and $\mathrm{D}$, upper traces are superposed reproduction of the intracellular and extracellular records in $\mathrm{A}$ and $\mathrm{B}$, respectively. Their differences are shown in the lower traces. Downward arrows in D indicate the moment of onset of IPSP which was determined by observing the changes in these potentials during passage of a hyperpolarizing current across the membrane $\left(2 \times 10^{-8} \mathrm{~A}\right)$, for the IPSP was changed to a depolarizing potential under membrane hyperpolarization. 

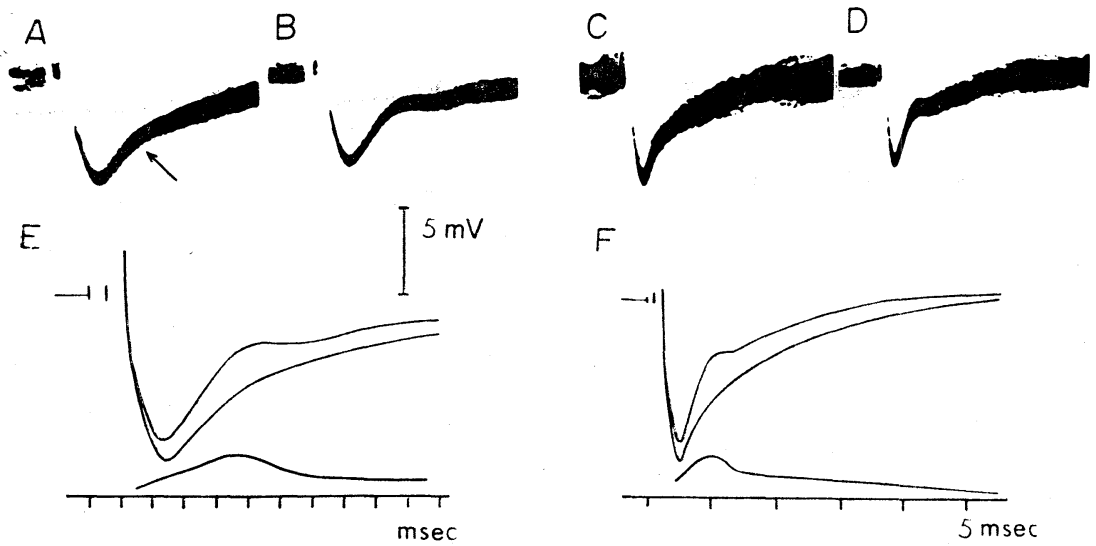

FIG. 9. A and B, afterpotential and EPSP produced by the ipsilateral $\mathrm{C}_{3}$ stimulation. In $\mathrm{A}$ the stimuli were just above the threshold for the axon of the impaled cell and in $B$ four times as large as the former. $C$ and $D$, the same potential changes as in $\mathrm{A}$ and $\mathrm{B}$ but recorded with a slower sweep velocity. $\mathrm{E}$ and $\mathrm{F}$, superimposed tracings of $\mathrm{A}-\mathrm{B}$ and $\mathrm{C}-\mathrm{D}$, respectively. The differences between $\mathrm{A}$ and $\mathrm{B}$ and between $\mathrm{C}$ and $\mathrm{D}$ are reproduced in the lower traces in $\mathrm{E}$ and $\mathrm{F}$.

covered more than $4.6 \mathrm{~cm}$ (distance from the $\mathrm{C}_{3}$ to Deiters' nucleus, see above) during the remaining $0.5 \mathrm{msec}$, that is, it travelled at a conduction velocity of $100 \mathrm{~m} / \mathrm{sec}$ or so. When the stimulus strength was increased over the threshold for the axon of the impaled cell, the phase of the afterhyperpolarization following the spike was often seen to be changed by superimposed PSPs. In FIG. 9A and B or C and D potential changes were recorded at slow sweep velocity with stimuli only slightly above the threshold and then four times respectively. These two sets of records are superimposed in FIG. $9 \mathrm{E}$ and $\mathrm{F}$ and reveal an early occurrence of an EPSP, which is apparently monosynatic and similar to that in FIG. 8. These presumed monosynaptic EPSPs were found in seven out of fourteen cases (50\%) examined with stimuli supramaximal for the antidromic field potential. On the other hand, an IPSP was revealed to occur in four out of the same fourteen cells (28.6\%). FIG. 8B and $D$ gives an example of an IPSP which curtails the falling phase of the monosynaptic EPSP. The latency of such IPSP as this has never been less than $4.5 \mathrm{msec}$, indicating a polysynaptic origin.

In the case of FIG. $7 \mathrm{~A}-\mathrm{D}$, the ipsilateral $\mathrm{C}_{3}$ stimulation failed to induce PSPs even with the supramaximal intensity for the antidromic field potential. Nor was there significant potential change by stimulation at the middle $\mathrm{C}_{3}$ electrode (FIG. 7C). On the other hand, a sequence of a brief EPSP and a long-lasting IPSP at a latency of $8 \mathrm{msec}$ was produced by the contralateral $\mathrm{C}_{3}$ stimulation (FIG. 7D). These PSPs were characterized by large spontaneous fluctuations of their size, they were even abolished intermittently under constant stimulating conditions. The same type of PSPs were of ten induced by 
stimulating at the middle $\mathrm{C}_{3}$ electrode, but not from the ipsilateral side except for a very few cases. Evidence has been obtained that the pathway of inducing the IPSP from the contralateral $\mathrm{C}_{3}$ segment includes the cerebellar cortex (ITO \& OBATA, unpublished).

Even when no stimulus was given to the spinal cord, there were usually irregular fluctuations of the membrane potential to the extent of a few millivolts (FIG. 5I). These potential changes were presumed to be caused by the spontaneous bombardment to the presynaptic terminals (cf. BRock, COOMBS \& ECCLES, 1952).

\section{DISCUSSION}

Antidromic activation has been widely used in the vertebrate central nervous system as the most reliable method of identifying a selected neurone group (LoRente de Nó, 1947 ; Barakan, Downman \& Eccles, 1949; Lloyd, 1951; FATT, 1957; MAGNI \& Willis, 1963). In the present experiments the nucleus of Deiters was specified by the negative field potential caused antidromically by stimulating the ipsilateral $\mathrm{C}_{3}$ segment that includes the vestibulospinal fibres. Within the area generating the conspicuous field, microelectrodes were inserted into the units which could be identified as Deiters' neurones by the following criteria; 1) they were activated at a short latency around $0.9 \mathrm{msec}$ from the ipsilateral $\mathrm{C}_{3}$ segment; 2 ) the intracellularly recorded spike showed a characteristic pattern of the antidromic M-IS-SD conduction; 3 ) the spike was followed by an afterhyperpolarization, the mean size of which relative to the spike height, $4.3 \%$, was comparable with $4.5 \%$ in cat spinal motoneurones (BRock et al., 1953) and much larger than $0.2 \%$ in mammalian A fibres (GASSER \& GRUNDFEST, 1936); 4) beside the synaptic noises spontaneously arising, PSPs were induced by stimulating the spinal cord, the vestibular nerve (ITO, HONGO \& OKADA, in course of preparation) and the cerebellum (ITO \& YoshidA, 1964).

The antidromic activation of Deiters' neurones provided a way of distinguishing their somatotopical innervation and of appraising their relative sizes by the axonal conduction velocities. In these respects there was excellent agreement between the histological data by BRODAL and his colleagues and the present physiological observations; 1 ) the vestibulospinal tract is exclusively homolateral; 2) the nucleus of Deiters includes neurones of various sizes which send axons into the spinal cord; 3) there is clear somatotopical arrangement within the nucleus, but the integrated negativity of the antidromic field potential showed a considerable overlapping between the components induced from the lumbosacral and cervicothoracic segments, respectively. This could in part be due to the dendritic structures which spread out of individual neurones over the stretch up to $700 \mu$ (MANnEN, 1964). However, 
the negativity does not spread beyond $300 \mu$ around a single spinal motoneurones (FATT, 1957 ; NELSON, FRANK \& RALL, 1960) in spite of the fact that its dendritic trees may extend up to $1 \mathrm{~mm}$ or so. Therefore, intermingled dendrites probably are not the main cause of the overlapped component field potentials, but there should be overlapping between the cell populations of different somatotopical origins, as was already pointed out histologically (Pompeiano \& Brodal, 1957a). This view was supported by the fact that the neurones activated from the $\mathrm{L}_{1}$ level were found not only in the dorsal but also in the ventral portion of the nucleus where the $\mathrm{L}_{1}$-induced antidromic field was smaller than that caused from the cervicothoracic levels.

The performance of Deiters' neurones during antidromic activation closely resembles that of cat spinal motoneurones. However, the time course of the action potential was significantly faster than that of spinal motoneurones; the duration of the spike was $0.46 \mathrm{msec}$ on the average against $0.67 \mathrm{msec}$ for the fast motoneurones and $0.9 \mathrm{msec}$ for slow ones (KUNO, 1959), though, because of the difference in the method of measuring the spike duration, the discrepancy between Deiters' neurones and fast motoneurones would be somewhat smaller than that indicated by these figures (see Results); the summit time of the afterhyperpolarization was $0.7-8.8 \mathrm{msec}$ against $10-15 \mathrm{msec}$ (BROcK et al., 1952) or 6-15 msec (Kuno, 1959); the total duration of the afterhyperpolarization was 33-100 msec compared with 50-180 msec (ECCLEs et al., 1958) or 40-195 msec (Kuno, 1959). Among motoneurones these factors vary according to their grade of the slow-fast characteristics (Eccles et al., 1958; Kuno, 1959; Eccles et al., 1961). In this respect, Deiters' neurones may be ranked at the extreme of the fast type of neurones. This would be relevant to the finding that the Deiters' neurones discharged spontaneously at a frequency up to $400 \mathrm{c} / \mathrm{s}$. It is conceivable that under physiological conditions Deiters' neurones control the spinal motoneurones tonically by sending down impulses at frequencies of wide range.

In the present experiments an early occurrence of EPSP, presumably monosynaptic, was found in $50 \%$ of the cells examined during ipsilateral $\mathrm{C}_{3}$ stimulation that was strong enough to induce supramaximally the field potential of Deiters' nucleus. Such a strong stimulus as this might have excited the ventral and lateral funiculi, for it was shown to involve even the contralateral vestibulospinal fibres (FIG. 3A). It is therefore likely that the EPSP was produced through a certain spinal tract which makes direct contact on Deiters' neurones. Indeed, according to POMPEIANO \& BRODAL (1957b), Deiters' neurones, particularly those in the caudal portion of the nucleus, are impinged by fibres ascending homolaterally with the dorsal spinocerebellar tract. These fibres may be collaterals of the dorsal spinocerebellar fibres (LORENTE DE NÓ, 1924), but there may be also some direct spinovestibular fibres (POMPEIANO \& BRODAL, 1957b). 
It has been shown histologically that the axon collaterals of the vestibulospinal tract enter the medial vestibular nucleus (CAJAL, 1909; LORENTE DE NÓ, 1933) and the descending nucleus (LORENTE DE Nó, 1933). It is well known that the axon collaterals of spinal motoneurones exert an inhibition through the Renshaw cell pathway (Eccles, FATT \& KoKeTsu, 1954). Those of pyramidal cells in the motor cortex (PHILliPs, 1959) and the hyppocampal cortex (KANDEL, SPEnSER \& BrINLEy, 1961) and of thalamic neurones (ANDERSEN \& ECCLES, 1962) also receive powerful recurrent inhibition. In Deiters' neurones, however, IPSPs were observed to occur in only $7.7 \%$ of the cells examined with the stimulus intensity subthreshold for their axons. Even though the percentage increased to $28.6 \%$ with stronger stimulus intensity, there was occurrence of monosynaptic EPSPs at a higher percentage, presumably through the spinovestibular fibres (see above). Therefore, it can not be concluded that the observed IPSPs were induced through the axon collaterals of the vestibulospinal fibres. The scarcity of the IPSP at relatively low stimulus intensity would rather suggest that, at least under the present experimental conditions, the axon collaterals of Deiters' neurones do not produce the recurrent inhibition. Lack of the recurrent inhibition has recently been demonstrated in phrenic motoneurones in spite of the presence of the axon collaterals (GILL \& KUNO, 1963). It is interesting that the duration of the afterhyperpolarization is relatively short in phrenic motoneurones, being in the range of the fast lumbosacral motoneurones, and that it is even shorter in Deiters' neurones. Therefore, the rule obtained for the lumbosacral motoneurones would be extended to the phrenic as well as to Deiters' neurones that the amount of the recurrent inhibition which they receive decreases as the duration of the afterhyperpolarization shortens (KunO, 1959; ECCLES et al., 1961). This again is in accord with the fast characteristics of Deiters' neurones (see above).

\section{SUMMARY}

1. Glass microelectrodes were inserted into the lateral vestibular nucleus of Deiters, and potential changes were recorded both extracellularly and intracellularly under stimulation of the spinal cord.

2. When the ipsilateral $C_{3}$ segment was stimulated at its ventrolateral surface, negative field potentials of several millivolts were recorded from the area which was histologically identified as Deiters' nucleus. These field potentials were presumed to be caused by the antidromic activation of Deiters' neurones through the vestibulospinal tract.

3. The antidromic field potential of Deiters' nucleus showed different distributions in the ventrodorsal direction for activation at the $C_{3}$ and $L_{1}$ levels, which is in keeping with the histologically determined somatotopical arrange- 
ment.

4. Within the nucleus of Deiters specified by the field potentials, a total of 134 units were impaled with microelectrode. They were identified as Deiters' neurones by the characteristics of the antidromic spikes, their afterhyperpolarization and by occurrence of synaptic noise and PSPs.

5. In sixteen selected neurones the resting potential was -55 to $-75 \mathrm{mV}$ and the spike height 60 to $100 \mathrm{mV}$ (mean, $80.8 \mathrm{mV}$ ). The duration of the spike was 0.4 to $0.6 \mathrm{msec}$ (mean, $0.47 \mathrm{msec}$ ).

6. The conduction velocity along the vestibulospinal fibres was determined in fifty Deiters' neurones which were activated antidromically both from the $\mathrm{C}_{3}$ and $\mathrm{L}_{1}$ segmental levels. It ranged from 24 to $140 \mathrm{~m} / \mathrm{sec}$, the peak frequency being at 90 to $100 \mathrm{~m} / \mathrm{sec}$.

7. The falling phase of the spike, after it crossed the base line, reversed to an afterhyperpolarization which reached its summit at 0.7 to $8.8 \mathrm{msec}$ (mean, $2.4 \mathrm{msec}$ ), and diminished within 33 to $100 \mathrm{msec}$ (mean, $49 \mathrm{msec}$ ). These values are smaller than those for cat spinal motoneurones. As a unique feature in Deiters' neurones the afterhyperpolarization did not show a temporal summation when it was evoked successively at short intervals.

8. The stimulation of the ipsilateral $C_{3}$ segment just subthreshold for the axon of the impaled cells induced EPSPs monosynaptically in $15.4 \%$ and IPSPs polysynaptically in $7.7 \%$ of the examined neurones. The recurrent axon collaterals might be responsible for these IPSPs, but the possibility was not excluded for the other pathways.

9. Stimulation at the $\mathrm{C}_{3}$ segment supramaximal for the antidromic field potential of Deiters' nucleus produced monosynaptic EPSP in $50 \%$ and polysynaptic IPSP in $28.6 \%$. It was suggested that the monosynaptic EPSP was produced through the ascending tract fibres in the spinal cord.

10. In view of the fast time course of the action potential and of rarity of the possible recurrent inhibition, it was postulated that Deiters' neurones would be grouped with the fast type of lumbosacral motoneurones.

The authors are indebted to Prof. K. UCHizono for his constant encouragement during the course of this investigation and for reading this manuscript. They are also much obliged to Prof. Sir John Eccles for kindly reading this manuscript and improving English. A part of the expense for this investigation was supplied by the Educational Ministry.

\section{REFERENCES}

Andersen, P. AND Eccles, J.C. Inhibitory phasing of neuronal discharge. Nature, Lond., $196:$ 645-647, 1962.

Araki, T., Eccles, J.C. AND ITO, M. Correlation of the inhibitory postsynaptic potential of motoneurones with the latency and time course of inhibition of monosynaptic reflexes. J. Physiol., $154: 354-377,1960$. 
Barakan, T.H., Downman, C.B.B. And Eccles, J.C. Electric potentials generated by antidromic volleys in quadriceps and hamstring motoneurones. J. Neurophysiol., 12 : 393-424, 1949.

BRoCk, L. G., Coombs, J.S. ANd Eccles, J.C. The recording of potentials from motoneurones with an intracellular electrode. J. Physiol., 117: 431-460, 1952.

Brock, L. G., Coombs, J.S. ANd Eccles, J.C. Intracellular recording from antidromically activated motoneurones. J. Physiol., 122: 429-461, 1953.

Brodal, A., Pompeiano, O. And Walberg, F. The vestibular nuclei and their connexions. C. C. Thomas, Springfield, 1962.

Brodal, A. And Pompeiano, O. The vestibular nuclei in the cat. J. Anat., 91: 438454, 1957.

CAjal, S. RAmón, Y. Histologie du systeme nervoeux de l'homme et des vertébrés. Maloine, Paris, 1909-11.

Coombs, J.S., Curtis, D. R. And Eccles, J.C. The interpretation of spike potentials of motoneurones. J. Physiol., 139: 198-231, 1957.

Coombs, J.S., Eccles, J.C. AND FAtT, P. The electrical properties of the motoneurone membrane, J. Physiol., 130: 291-325, 1955.

CRAIN, S.M. Resting and action potentials of cultured chick embryo spinal ganglion cells. J. comp. Neurol., $104: 285-330,1956$.

Eccles, J.C. The Physiology of Nerve Cells. The Johns Hopkins Press, Baltimore, 1957.

Eccles, J. C., Eccles, R. M., IgGo, A. And Ito, M. Distribution of recurrent inhibition among motoneurones. J. Physiol., 159: 479-499, 1961.

Eccles, J.C., Eccles, R. M. And Lundberg, A. The action potentials of the alpha motoneurones supplying fast and slow muscles. J. Physiol., 142:275-291, 1959.

Eccles, J.C., Fatt, P., Landgren, S. and Winsbury, G. J. Spinal cord potentials generated by volley in the large muscle afferents. J. Physiol., 125:590-606, 1954.

Eccles, J.C., Fatt, P. AND Koketsu, K. Cholinergic and inhibitory synapses in a pathway from motor axon collaterals to motoneurones. J. Physiol., 126: 524-562, 1954.

Eccles, J.C. AND KRnJEvić, K. Potential changes recorded inside primary afferent fibres within the spinal cord. J. Physiol., 149: 250-273, 1959.

FATT, P. Electrical potentials occurring around a neurone during its antidromic activation. J, Neurophysiol., $20: 27-60,1957$.

FreYGANG, W. H. Jr. An analysis of extracellular potentials from single neurons in the lateral geniculate nucleus of the cat. J. gen. Physiol., $41: 543-564,1958$.

FrEYGANG, W. H. Jr. AND Frank, K. Extracellular potentials from single spinal motoneurons. J. gen. Physiol., 42: 749-760, 1959.

Gasser, H.S. And Grundfest, H. Action and excitability in mammalian A fibers. Amer. J. Physiol., 117: 113-133, 1936.

Gernandt, E., Iranyl, M. and Livingston, R.B. Vestibular influences on spinal mechanisms. Exp. Neurol., 1: 248-273, I959.

Gernandt, E. and Gilman, S. Descending vestibular activity and its modulation by proprioceptive, cerebellar and reticular influences. Exp. Neurol., 1:274-304, 1959.

Gill, P.K. And Kuno, M. Properties of phrenic motoneurones. J. Physiol., 168: 258273, 1963.

Granit, R. And Phillips, C.G. Excitatory and inhibitory processes acting upon individual Purkinje cells of the cerebellum in cats. J. Physiol., 133: 520-547, 1956.

Hursh, J.B. Conduction velocity and diameter of nerve fibers. Amer. J. Physiol., 127 : 131-139, 1939.

ITO, M. An analysis of potentials recorded intracellularly from the spinal ganglion 
cell. Jap. J. Physiol., 9: 20-32, 1959.

ITo, M. New electronic device for stimulation and recording potentials for a single spinal ganglion cell. In Medical Electronics. pp. 84-85, ed. by Smyth, C. N. Iliffe, London, 1960.

Ito, M., Hongo, T., Yoshida, M., OKada, Y. And Obata, K. Intracellularly recorded antidromic responses of Deiters' neurones. Experientia, 20:295-296, 1964.

Ito, M. And Oshima, T. Temporal summation of after-hyperpolarization following a motoneurone spike. Nature, Lond., 195: 910-911, 1962.

Ito, M. And Yoshida, M. The cerebellar-evoked monosynaptic inhibition of Deiters' neurones. Experientia, 20: 515-516, 1964.

Kandel, E. R., Spencer, W. A. And Brinley, F.J. Jr. Electrophysiology of hyppocampal neurons. I. Sequential invasion and synaptic organization. J. Neurophysiol., 24 : 225-242, 1961.

Kuno, M. Excitability following antidromic activation in spinal motoneurones supplying red muscles. J. Physiol., 149: 374-393, 1959.

Lloyd, D.P.C. Electrical signs of impulse conduction in spinal motoneurones. J. gen. Physiol., 35 : 255-288, 1951.

LOREnte de Nó, R. Etudes sur le cerveau postérieur. III. Sur les connexions extracérébelleuses des fascicules afférents au cerveau, et sur la fonction de cet organe. Trav. Lab. Rech. Biol. Univ. Madr., 22 : 51-65, 1924. quoted from BRodal, PompeIANo \& WALBERG, 1962.

LORENTE DE Nó, R. The interaction of the corneal reflex and vestibular nystagmus. Amer. J. Physiol., 103 : 704-711, 1933.

LORENTE DE NÓ, R. Action potential of the motoneurones of the hypoglossus nucleus. J. cell. comp. Physiol., 29 : 207-288, 1947.

MAGNI, F. AND WILlis, W. D. Identification of reticular formation neurons by intracellular recording. Arch. ital. Biol., 101: 681-702, 1963.

Mannen, H. Arborisations dendritiques dans le noyau vestibulaire du chat. Etude topographique et quantitative. Arch. ital. Biol., in press.

Nelson, P. G. Frank, K. And Rall, W. Single spinal motoneuron extracellular potential fields, Fed. Proc., 19: 5, 1960.

Phillips, C. G. Action of antidromic pyramidal volleys on single Betz cells in the cat. Quart. J. exp. Physiol., 41: 1-25, 1959.

Pompeiano, O. And Brodal, A. The origin of vestibulospinal fibres in the cat. An experimental-anatomical study, with comments on the descending medial longitudinal fasciculus. Arch. ital. Biol., 95: 166-195, 1957a.

Pompeiano, O. And Brodal, A. Spinovestibular fibers in the cat. An experimental study. J. comp. Neurol., 108 : 353-382, 1957b.

Pompeiano, O. And Cotti, E. Analisi microelecttrodica delle proiezioni cerebellodeitersiane. Arch. Sci. biol., 43 : 57-101, 1959. quoted from Brodal, Pompeiano \& WALBERG, 1962.

Terzuolo, C.A. And ARaki, T. Analysis of intra-versus extracellular potential changes associated with activity of single spinal motoneurons. Ann. New York Acad. Sci. 94 : 547-558, 1961.

Vito, R. V. DE, Brusa, A. And Arduini, A. Cerebellar and vestibular influences on Deitersian units. J. Neurophysiol., 19: 241-253, 1956. 